\title{
A radioativa estufa de Mario Bellatin: o desabrochar de anômalas flores
}

\section{The radioactive greenhouse of Mario Bellatin: the blooming of anomalous flowers}

Luciane Bernardi de Souza ${ }^{1}$

https://orcid.org/0000-0002-2787-6630

Resumo: Neste trabalho, nos propomos discutir a presença do corpo deforme na obra Flores (2001), do escritor mexicano Mario Bellatin. Visamos problematizar como os corpos anômalos, assim como o espaço em que esses corpos frequentam, ao mesmo tempo em que sofrem o poder, através de inúmeros dispositivos, também desafiam as normas sociais da disciplina e do regramento. Tal contestação ocorre pela ressignificação das anomalias, que impulsionam uma busca por experiências do desejo e vivências que resistem e contestam a lógica da docilidade e da servidão. Para o diálogo, trazemos em nossa leitura as vozes de Michel Foucault, em especial seus pressupostos teóricos da esfera do biopoder, e Georges Bataille, com os conceitos de erotismo e continuidade.

Palavras-chave: Mario Bellatin; Biopolítica; Erotismo.

\footnotetext{
${ }^{1}$ Doutoranda pelo PPGLIT/UFSC. E-mail: lucibernardi@gmail.com
} 
Abstract: In this paper, we propose to discuss the presence of the deformed body in the work Flores (2001), by the mexican writer Mario Bellatin. We aim to problematize how anomalous bodies, as well as the space in which these bodies attend, while at the same time suffering power through numerous devices, also challenge the social norms of discipline and rule. Such contestation occurs by the resignification of anomalies, which drive a search for experiences of desire and experiences that resist and contest the logic of docility and servitude. For dialogue, we bring in our reading the voices of Michel Foucault, especially his theoretical assumptions of the sphere of biopower, and Georges Bataille, with the concepts of eroticism and continuity.

Keywords: Mario Bellatin; Biopolitics; Eroticism.

\section{Considerações iniciais}

A ideia de lidar com a orfandade e inexatidão de conceitos como deus, sentido, absoluto, totalidade e essência, torna-se insuportável segundo o modo como encaramos nossa existência no mundo, desde muito ancorada nessas apaziguáveis invenções lógicas-racionais do intelecto. É por essa razão que o ser humano, imerso em uma racionalidade desmedida, sempre teve a necessidade de conceituação e limitação daquilo que, em sua natureza, é ilimitado.

Avesso à necessidade conceitual-intelectual incomensurável, o discurso literário, provocativo em seu âmago e lugar privilegiado do questionamento dos limites e conceitos, conforma-se como um espaço de transgressão e reconfiguração das vivências e dos valores. Ao enfatizar o questionamento dos reais limites discursivos, nos leva a uma reflexão sobre a palavra e, consequentemente, sobre a (des)construção do mundo. A Literatura (em especial a contemporânea) abraça assim os paradoxos e as contradições, apresentando-se como um fértil terreno de conflito e reflexão dos limites e conceitos não apenas estéticos, mas morais, éticos, culturais e sociais.

Se a linguagem com fim prático tem por intenção ser limpidamente decifrável e lúcida, a estética possui em si o âmago da provocação, possibilitando lançarmos um olhar reinventivo sobre a palavra, avançando contra os princípios da ordem e de nossas tão abrandáveis certezas.

Nesse sentido, por acreditarmos na Literatura enquanto potência de reinvenção da realidade, que possibilita o questionamento do verbo e da representação das experiências dos afetos e dos deslimites, privilegiamos esse lugar do extravio e do contrassenso, lançando um olhar atento sobre a obra Flores (2001), do escritor latino-americano Mario Bellatin. A partir deste corpus literário buscamos problematizar como a presença de personagens anômalos em lugares de transgressão, ao mesmo tempo que explicita a tentativa de normalização e disciplina sobre o desigual, desestabiliza e contesta a lógica do controle, desafiando as tecnologias e os 
dispositivos de poder que atuam sobre o corpo (de)formado e sobre os lugares de vivências alternativas.

Para isso, orientamos nossa leitura a partir dos pressupostos teóricos foucaultianos da esfera do biopoder, visualizando como nas narrativas de Flores as personagens se apoderam das consequências materiais das enfermidades/anomalias, as ressignificam e tentam buscar um novo corpo, que interroga biopoliticamente a vida. Tal fenômeno de questionamento e ressignificação, que se estende também para os espaços que essas personagens frequentam, desviam os mecanismos sociais de controle e resistem à regulação social, política e cultural. Nesse sentido, Flores apresenta corpos e espaços que ao mesmo tempo em que sofrem as dimensões coercitivas do poder, se apresentam como resistentes a ele.

Por trabalharmos a partir de um corpus construído pelo discurso estético, esta discussão sobre o corpo como lugar de resistência às normas sociais impostas, nos impulsiona para uma reflexão sobre a palavra como lugar da racionalidade e homogeneidade, mas também como locus da transgressão e questionamento das verdades estabelecidas, reflexão presente nos escritos do filósofo alemão Friedrich Nietszche e que neste trabalho, além de estabelecer as bases para a reflexão, também dialoga com o conceito de biopolítica, de Michel Foucault, e de erotismo e continuidade, do teórico Georges Bataille. Nesse sentido, à luz das noções biopolíticas foucautinanas e, em proximidade com as reflexões de Georges Bataille, consideramos como em algumas narrativas de Flores se estabelecem as relações de forças entre existências, afetos e saberes, cujo motor de construção e resistência é a palavra em sua potência estética.

\section{Fundamentação teórica}

Friedrich Nietszche, filósofo do século XIX, afirmava ser preciso repensar a história do conhecimento humano, a história da racionalidade, a história da filosofia. "Filósofo-dinamite" como ele mesmo se autodenominava, acreditava que a nossa civilização seria vítima (e paradoxalmente também algoz) de uma interpretação restritamente socrática do mundo, uma vez que construimos uma imagem de nós mesmos muito superior ao que realmente somos. Tal certeza se tornou uma verdade ainda maior para o filósofo à medida que ele se debruçou sobre o modelo de vida dos gregos pré-socráticos, que, segundo a sua leitura, defendiam aquilo que acabamos por extinguir: uma vivência fundada no devir e na crença da vida (desconhecida e intensa) como processo de transformação constante.

Filósofo do paradoxo e defensor das contradições infinitas, questionou toda a 
prepotência do conhecimento arquitetado pelo homem moderno ao pôr em xeque as bases do racionalismo ocidental e do antropocentrismo: “Nós, que somos homens do conhecimento, não conhecemos a nós próprios; somos de nós mesmos desconhecidos e não sem ter motivo. Nunca nós nos procuramos: como poderia então que nos encontrássemos algum dia?" (2016, p.02). Friedrich Nietszche defendeu assim um pensamento marcado pelo corpo e pela arte, negando a pretensão de controlarmos a natureza e a vida, vistas como inexplicáveis, irracionalizáveis e sempre superiores ao homem.

A constatação de que nossa civilização, que considera a razão e o saber como infalíveis motores de busca incessante pela verdade, é modelada a partir de um pensamento estritamente lógico e excludente do prazer, leva Nietzsche a afirmar que a história do pensamento humano é a busca por uma verdade que somente pode ser atingida pela via do pensamento, e não das sensações. Logo, como seres do pensamento e da palavra, temos necessidade de justificar, racionalizar e explicar a vida em todos os seus âmbitos, explicações somente possíveis através do uso racional e restrito da linguagem.

Em concordância com o pensamento do filósofo alemão, o teórico francês Michel Foucault ressalta que para suportarmos a vida, fez-se necessária a irremediável busca por um fundamento/essência, produto do nosso medo da morte e da necessidade de estabelecer no mundo a duração da vida. Racionalizamos o mundo, negamos o corpo, as sensações, o conflito, o devir e a instabilidade ao afirmarmos, a partir do signo e da linguagem, a construção de uma imagem idealizada de nós, do outro e do mundo. No entanto, essa linguagem que, depauperada e empobrecida de sentimentos, afetos e imagens, definha ao corroborar na construção desse baluarte racional, também carrega em si a potência para, senão implodir, minimamente minar e questionar as certezas humanas.

O discurso literário, ao apresentar estruturas (abismais, paradoxais, grotescas) para que possamos vivenciar o sofrimento, a morte e o trágico, acaba por desacomodar, mas também por fortalecer a vida e fazer com que reinventemos novas formas de ser e sentir. De tal modo, nos parece urgente que, a partir do discurso literário (re)criemos uma nova forma de relação com as palavras, de modo a desautorizá-las e desmistificá-las, deixando brotar e (re)nascer delas uma expressão cheia de contradição, cheia de instante.

É por não fugir e negar a tempestuosidade de afetos e sensações, que o discurso de Flores convoca as palavras livres, apresentando imagens do feio, do caos, do grotesco e do instável, por meio de um discurso que não cabe na linguagem adoecida pela lógica e pela razão, ao sobrelevar mundos e sujeitos incompletos, marcados pela falta e pela busca.

Com modos peculiares de narrar e conceber a prática literária, Mario Bellatin nos 
remete a um discurso lodoso e impregnado de forças simbólicas, discurso no qual braveja em escarcéu corpos em constante atrito com o meio, corpos em explosão, deformação e reconstrução, corpos que urgem pelo preenchimento da ausência. Enfermos, mutilados e/ou anômalos, esses corpos bellatinianos impulsionam sua existência a partir de uma falta inicial, a partir da ausência de um membro do corpo ou da família, de uma falta ou anomalia gerada pela doença, morte ou privação do estado, representando assim aquele que não tem o poder de direito, o excluído socialmente, o ensimesmado, ao qual é muitas vezes negado o poder de participação social.

No entanto, é justamente a partir dessas carências lacunares, materiais ou imateriais, que se desenvolvem nas personagens potências de desejos e fantasias que se manifestam a partir da busca de vivências que possibilitam a experiência, com o outro e consigo, de modo mais intenso, a experiência da "continuidade", conceituada e teorizada por Georges Bataille. Esses corpos anômalos, para vivenciar experiências de vida que geram a supressão das faltas, frequentam lugares que funcionam ao nível dos afetos: a mesquita visitada pelo escritor (na qual este personagem realiza giros que o levam a uma experiência de transcendência), a Hell Kitchen e os Altares, lugares que se localizam nas zonas marginais da cidade, funcionam como espaços de resistência e possiblidade de vivências alternativas. Fugindo às normas, eles combinam com as transgressões dos corpos anômalos, que são o elemento central deste nosso estudo.

\section{Corpos em (de)formação, corpos em (re)pressão}

Complexo, incerto e ambíguo, o fenômeno da corporeidade, conclama o diálogo interdisciplinar entre as diversas ciências: sociais, humanas e biomédicas. Investigar e compreender o corpo humano, esse inesgotável depósito de construção de imaginários, repleto de simbolismo e representações, é inseri-lo na trama incessante dos sentidos como um fenômeno cultural e social que inexiste em estado natural. Na obra A sociologia do corpo (2003), o teórico francês David Le Breton afirma que o corpo é um símbolo da sociedade, uma vez que "reproduz em escala reduzida os poderes e os perigos que se atribui à estrutura social. O corpo metaforiza o social e o social metaforiza o corpo. No interior do corpo são as possibilidades sociais e culturais que se desenvolvem" (2003, p.70).

De tal modo, é pensando o corpo como centro das práticas de poder e partindo da noção de poder como uma potência que se manifesta através das relação de força em todos os âmbitos, inclusive nos menores (relações capilares), que o teórico francês Michel Foucault cunhou o conceito de biopolítica, que permite que o Estado e as instituições, ainda que 
sutilmente, invadam a vida privada das populações para, segundo seus propósitos, determinar politicamente que tipos de vida merecem viver.

Retomado e redefinido por inúmeros autores, o conceito foi inicialmente apresentado pelo teórico francês ao grande público em 1976, no último capítulo de História da Sexualidade I, A vontade de saber, desenvolvido em um curso proferido no Collège de France, publicado postumamente como "Em defesa da sociedade". A partir dele, Michel Foucault apresenta os mecanismos de poder sobre o indivíduo (disciplinarização) e sobre a população (biopolítica), e afirma que foi a partir do século XX que as práticas biopolíticas se apresentaram de uma maneira que associavam a luta pela vida a uma prática de exclusão e morte, uma vez que visavam proteger a vida dos riscos, conflitos e paixões, elementos estes tão comuns (e necessários) nas relação humanas.

Segundo Michel Foucault, o poder é exercido através de relações que adentram o âmbito privado e cotidiano, acarretando em um controle sobre os corpos e a população e promovendo a vida a partir de um custo que é o controle da própria vida, para que haja somente corpos dóceis e produtivos. A fim de governar os seres, as sociedades disciplinam e produzem corpos exercendo sobre eles o poder e a norma, visando enquadrar, classificar, modificar e até mesmo segregar esses corpos, se necessário for. Segundo o teórico:

\footnotetext{
O controle da sociedade sobre os indivíduos não se efectua somente pela consciência ou pelo ideológico, mas também no corpo e pelo corpo. Para a sociedade capitalista, é o biopolítico que importava antes de mais nada, a biológica, o somático, o corporal. O corpo é uma realidade biopolítica (FOUCAULT, 1989, p. 82).
}

Assim, é necessária a aniquilação da doença, do mal-estar, da deformidade, daquilo que torna os corpos não-homogêneos, assim como é necessário o refreamento de práticas (sexuais, espirituais) dispendiosas de energia, pois, sem a liberação dos desejos, nos tornamos corpos sempre mais dóceis e mais produtivos. Tal modelo de existência, afirma um modelo de vida imposto (pelas instituições, pelo estado) que acredita que determinadas vidas valem mais: as vidas sem vidas, sem paixões, sem conflito e biologicamente "superiores".

Em Flores, algumas personagens tornam-se explicitamente vítimas desse modelo social excludente e homogêneo: o escritor, vítima de uma anomalia congênita causada por um medicamento (fármaco este que visava acabar com o enjoo em mulheres grávidas), é uma personagem que sofre com a incapacidade que temos de não conseguirmos lidar com o diferente. A rejeição social de seu corpo-anômalo (nasceu sem uma das pernas, e seu irmão, 
gêmeo, sem os braços) inicia logo ao nascer, quando é abandonado pela figura paterna, que o percebe deformado:

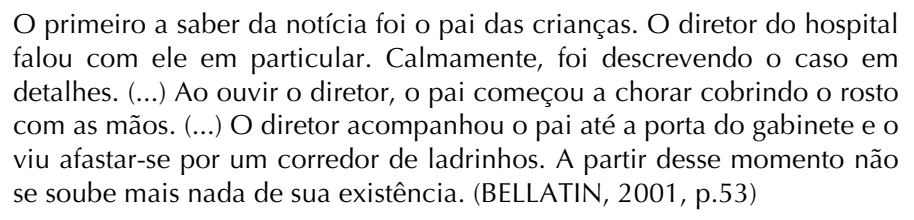

Já adulto, pesquisando sobre sexualidades alternativas em uma zona da cidade denominada de Hell kitchen, ele descobre que sua pesquisa é uma estratégia do governo para violar a privacidade das pessoas que realizavam práticas sexuais alternativas neste local e usálas como pretexto para interditar o espaço:

Como resultado de recentes medidas governamentais, a zona da cidade conhecida como Hell kitchen está prestes a desaparecer. Por isso, o escritor tem cada vez mais dificuldades para localizar pontos de encontro de pessoas que praticam sexualidades alternativas, por assim dizer. Prestou queixa, denunciando essa decisão das autoridades como uma ingerência ilegal na vida privada dos cidadãos (BELLATIN, 2001, p.33).

O Amante Outonal, outra personagem de grande importância dentro da obra, busca vivenciar o prazer de modo não convencional através de distintas experiências sexuais em rituais sadomasoquistas, nos quais as pessoas que se vestem de idosos, inclusive ele. No entanto, a força do poder que atua sobre a personagem atinge o nível físico, ao sofrer agressões por travestir-se:

\begin{abstract}
abandonou essa prática ao ser apunhalado por um ancião com quem entrou no elevador de um edifício vetusto. Depois de passar algumas semanas no hospital permaneceu trancado em seu apartamento até ficar totalmente curado dos ferimentos. (...) meses depois das punhaladas decidiu vestir-se como uma anciã. (BELLATIN, 2001, p.09).
\end{abstract}

Nessa estufa bellatiniana, cujas flores parecem crescer sob uma atmosfera radioativa altamente contaminante, encontramos os gêmeos Kuhn, seres que, adotados pela poeta, são resultado de uma relação incestuosa, forçada, entre dois irmãos, e que por não possuírem braços nem pernas foram abandonados em um orfanato após o nascimento. Além da rejeição que sofrem devido ao corpo anômalo, nesse lugar, por sua vez, continuam a sofrer a rejeição e a disciplinarização sobre seus deformados corpos:

O orfanato contava com um grupo de voluntárias que colaboravam adotando simbolicamente algumas das crianças reclusas. Era proibido 
levá-las à rua. (...) Podiam educá-los com surras ou reprimendas. Tinham o direito de fazer com que comessem, mesmo à força, os alimentos que levam em embalagens térmicas e vasilhas de plástico. (BELLATIN, 2001, p.17)

Vivenciadas pelas personagens, estas situações nos permitem visualizar alguns processos de repressão, disciplinamento e violência que ocorrem por tais personagens apresentarem-se destoantes em relação aos modelos e padrões socialmente impostos, e que passam a ser vistas, inclusive por pessoas mais próximas, como um desacômodo, uma ameaça à população padronizada e disciplinada.

\section{A busca do (des)contínuo: o eu no outro}

Como consequência (ou causa) das forças do disciplinamento, essas personagens não negam a experiência da continuidade. Consideradas inferiores ao se desviarem das vivências de prazer consentidas, essas vidas abraçam o instinto da carne, da passionalidade e não temem a imposição da supremacia da ordem e do padrão. Beatriz Preciado, em seu importante escrito "Multidões Multidões Multidões queer: notas para uma política dos "anormais" (2011) afirma que

\footnotetext{
o corpo não é um dado passivo sobre o qual age o biopoder, mas antes a potência mesma que torna possível a incorporação prostética dos gêneros. A sexopolítica torna-se não somente um lugar de poder, mas, sobretudo, o espaço de uma criação na qual se sucedem e se justapõem os movimentos feministas, homossexuais, transexuais, intersexuais, transgêneros, chicanas, pós-coloniais... As minorias sexuais tornam-se multidões. (PRECIADO, 2011, p.11)
}

Preciado acredita na força de resistência que as multidões possuem, na força dos corpos que, considerados território do desvio e do desajuste, pertencem ao campo da vida que segundo o direcionamento do biopoder, deve ser aniquilado da sociedade. Nesse sentido, nos interessa visualizar como ocorrem as experiências de transgressão das personagens de Mario Bellatin, que parecem vivenciar experiências do excesso no âmbito religioso, de criação estética e principalmente sexual.

Em sua obra O Erotismo, o teórico francês Georges Bataille apresenta como elemento importante da vivência humana o conceito de erotismo: "o erotismo é a aprovação da vida até a morte" (2017, p. 35). Ao desenvolver esta reflexão, ele afirma que toda a operação do erotismo tem por fim atingir o ser no mais íntimo, uma vez que somos seres intrinsecamente individuais 
e únicos: nascemos e morremos sós e independente da troca que realizamos com o outro, somos solitários e isolados. Bataille reitera essa noção ao afirmar que "Somos seres descontínuos, indivíduos que morrem isoladamente numa aventura ininteligível. Suportamos mal a situação que nos prende à individualidade fortuita, à individualidade perecível que somos". (2017, p.39). Assim, há um abismo entre eu e o outro, há uma descontinuidade, e a morte está ligada primeiramente a esse abismo que separa cada um de nós: abismo vertiginoso, vertigem face ao abismo, fascínio constante.

De acordo com Bataille, o erotismo se apresenta de três modos distintos: no corpo, no sagrado e nos corações. O erotismo dos corpos se realiza no ato sexual, em que ocorre a fusão dos corpos, em que nos fundimos com o outro num movimento de apagamento dos limites. O erotismo do coração, por sua vez, se realiza entre os seres apaixonados, que experimentam esse sentimento violento que é a paixão. No erotismo do coração, sofrimento e gozo se confundem, em função da intensidade, da desordem tão violenta, que o ser, se não correspondido, prefere até mesmo a morte. Já o erotismo sagrado, por sua vez, é conceituado do seguinte modo: “o sagrado consiste nessa busca de continuidade, ou seja, um ser descontínuo, limitado, incompleto, procurando a continuidade absoluta (2017, p. 144).

É esta realidade sagrada, erótica, abismal, que impulsiona o sujeito a buscar formas de continuidade, é desejo que nos integra a algo e possibilita experiências de continuidade, que faz nos integramos ao outro, ao todo, a uma totalidade que não nos pertence, a uma nostalgia da continuidade perdida: o indivíduo quer permanecer ele mesmo e, todavia, fundir-se com outro, mas, no mais profundo do ser, a fusão permanece como destruição, violência e morte. Experimentar a continuidade nos afasta da solidão e do isolamento, e nos leva à fusão com o outro e com o mundo, dada na superação dos limites (2017, p. 144).

Diretamente relacionados a esses conceitos de continuidade e descontinuidade, Georges Bataille apresenta também os de transgressão e interdição. As interdições, relacionadas ao campo das restrições sociais, têm uma relação próxima com o universo apolíneo do trabalho, que é o mundo da acumulação, da ordem e da disciplina, e que ao regrarem o mundo humano, são algumas das principais características que nos diferenciariam dos animais. Já a transgressão, segundo o teórico, se caracteriza pelo rompimento com das correntes das interdições, nos coloca em contato com a angústia e a sensação de pecado, e pode ser a porta de entrada para o erotismo.

As experiências e sensações de continuidade, que substitui o isolamento do ser e que podem ser experenciadas de diversos modos, sempre estão relacionadas ao erotismo e à transgressão do mundo homogêneo, que preza pela ordem e pureza. Segundo o teórico, a 
sociedade conseguiu organizar-se a partir do afastamento de nossa potência animal, sendo apenas a partir da negação (sempre parcial) e do controle das forças instintivas que teria ocorrido a constituição do ser propriamente humano. É inegável que precisamos de leis e proibições para que sobrevivamos em sociedade, caso contrário viveríamos em caos permanente. Assim, é imprescindível enfatizar que não podemos viver sem trabalho, sem lei, mas que também não podemos viver sem a força do erotismo.

No entanto, essa necessidade humana intrínseca, que se refere à busca pelo extravasamento, pela ruptura de limites e pelo abandono temporário da lei, pertence ao espaço do corpo, do sagrado e do erótico. Tal necessidade, no entanto, que se opõe ao mundo da razão e do regramento, é cada vez mais é negada e nulificada pelo mundo do trabalho, que refreia o prazer humano. É esse mundo da individuação e das leis que nos separa uns dos outros, que nos separa do erótico e do sagrado, e que pode ser denominado de mundo da descontinuidade, por nos afastar do contato com o outro e com experiências extremas que nos levam ao contato com nós mesmos e com um todo.

De acordo com Bataille, a vivência e imersão no mundo da continuidade, do erotismo, do sagrado, nos provoca a dissolução (ainda que temporária) da individualidade, que pode ser considerada uma possibilidade de acesso às forças das quais nos separamos em tempos míticos:

O mundo sagrado não é, em certo sentido, senão o mundo natural subsistindo na medida em que não é inteiramente redutível à ordem instaurada pelo mundo do trabalho, isto é, à ordem profana (...) o nascimento de uma nova ordem de coisas, provocado a contragolpe pela oposição à natureza do mundo da atividade útil. (BATAILLE, 2017, p. 35).

A experiência do deslimite e da transgressão, além de nos pôr em contato com nossa face mais genuína, desperta potências desagregadoras que, segundo a lógica do mundo do trabalho, são marcados pela inutilidade, pelo desperdício de energia. Essas experiências, reveladas através de situações extremas, vibram na direção do erotismo (do corpo, do sentimento, do místico), levando o indivíduo a subverter a individualidade do ser, e experenciar a continuidade, cuja expressão perpassa necessariamente a não sujeição verbal e a ruptura com os limites da linguagem.

O princípio da continuidade, pode assim não apenas se manifestar através de um discurso não calcificado, mas ser vivenciado através da linguagem, ainda que o discurso pareça obedecer a princípios de organização interna que limitam seu alcance ao mundo do trabalho. Para Bataille, o discurso teria uma grande potência de transgressão, em especial o discurso 
poético, uma vez que, ainda que alimentado e organizado pelos princípios racionais do homem, evidencia o lacunar, o tempestuoso, os silêncios:

\begin{abstract}
O discurso, se ele quiser, pode trazer a tempestade. (...) Ainda que as palavras drenem em nós quase toda a vida - desta vida, quase nenhum raminho que não tenha sido apreendido, arrastado, juntado pela multidão sem descanso destas formigas (as palavras). Na região das palavras, do discurso, esta parte é ignorada. Por isso, ela geralmente escapa. Só podemos em certas condições atingi-la ou dispor dela. São movimentos interiores vagos, que não dependem de nenhum objeto e não têm intenção, estados que, semelhantes a outros ligados à pureza do céu, ao perfume de um quarto, não são motivados por nada definível. Se bem que a linguagem que, a propósito dos outros, tem o céu, o quarto, ao qual se referir - e que, neste caso, dirige a atenção para o que ele apreende - fica despossuída, não pode dizer nada, limita-se a furtar desses estados à atenção (aproveitando a pouca acuidade deles, ela atrai logo a atenção alhures) (BATAILLE, 1992, p. 20 e 21)
\end{abstract}

Assim, de acordo com Bataille, as experiências do erotismo e do sagrado se apresentariam ao homem a partir de situações limites, nas quais se perde a possibilidade de controle e se vê muito próximo de forças obscuras que levariam à sensação de continuidade. Tais situações transgressoras, nas quais as forças culturais e sociais que regem a vida ordeira e racional são suspensas, permitindo a vivência do tempo festivo da transgressão, se explicitam através das vivências das personagens de Flores, que abraçam uma realidade que possibilita experiências febris.

\title{
A (des)continuidade
}

Investindo contra a descontinuidade do mundo do trabalho, contra a sensatez dos códigos e regras morais e do bom senso, que apregoam a moderação e sufocante controle, o escritor, ao mesmo tempo em que sofre, resiste aos mecanismos de poder, buscando vivências distintas. A personagem não se resigna diante das normas e do mundo da ordem, não teme o conflito da convivência social e a ausência de sentido da vida, nem a discordância às regras e aos valores impostos, mantendo-se cético em relação a qualquer discurso com pretensão de verdade.

Extremamente receptivo a experiências consideradas absurdas pela lógica racional, o escritor abraça uma existência crente nas potencialidades do ser. Um dos seus mecanismos de transgressão é o fato de inserir-se em diversos locais e manter sempre sua singularidade 
(vinculada a sua anomalia) vivenciando o excesso vinculados ao prazer e erotismo através de adornos e próteses que utiliza:

\begin{abstract}
o escritor, que nesta ocasião veste bermudas e usa a perna decorada com pedras artificiais. Apesar de todos os seus esforços, ninguém nunca parece disposto a perceber as possibilidades sádicas ou masoquistas que esse membro falso é capaz de propiciar (BELLATIN, 2001, p.09).
\end{abstract}

Esse escritor, que além de realizar suas fantasias justamente através da deformação que possui, também é adepto à religião muçulmana. Na mesquita que frequenta realiza os giros místicos, os quais o elevam espiritualmente, caracterizando uma experiência de continuidade, ainda que ele não siga todos os preceitos da religião.

Outra personagem de grande importância dentro da obra é o Amante Outonal, que o escritor conheceu numa noite em que estavam na frente de cabines pornôs. O Amante Outonal, "acredita que o paraíso é um lugar habitado por anciãos decrépitos dispostos, a um simples pedido, a mostrar suas bondades sexuais" (2001, p.14) e também busca vivenciar o prazer de modo não convencional. Esta personagem sente-se, desde muito cedo, atraído por idosos, e busca a concretização de suas fantasias em rituais sadomasoquistas.

Além disso, o fato de "frequentar alguns bares de sadomasoquismo, onde costumava ser o centro das atenções" (2001, p.41) e de que "gostava de sair à rua vestido de mulher. (BELLATÍN, 2000, p.09), impulsionam esse processo de resistência, continuidade e transgressão que esse personagem vivência nos lugares em que frequenta.

Em Flores, a arte desempenha um papel importante no âmbito da transgressão através da personagem Alba, uma poeta. Essa personagem, que possui a poesia como refúgio, encara o anômalo e não teme explorar e despertar os afetos e as sensações insondáveis, negadas pelo mundo homogêneo:

\footnotetext{
Alba começava a beber desde as primeiras horas da noite e não parava até o amanhecer. Quando visitava a cantina as coisas eram diferentes. Chegava à meia noite, levando na bolsa os poemas que escrevera nos dias anteriores. Sentava-se e, depois de beber um copo de aguardente, começava a leitura dos manuscritos (BELLATIN, 2001, p.59).
}

A força transgressora do discurso poético, aqui representada desmedida e destemidamente pela necessidade e urgência de criação da poeta Alba, nos apresenta o acolhimento da degenerada beleza de poesia que nasce do conflito, e que provoca um belo degenerado. 
Enquanto potência da linguagem, a poesia é capaz de proporcionar ao homem um canal de passagem do profano ao sagrado, da descontinuidade à continuidade, através de uma linguagem transformadora. Ao reagir contra a dureza racional do discurso cotidiano, ela nos possibilita o contato com uma linguagem que busca não reduzir a complexidade do mundo. Para Bataille, a poesia é, por excelência, um canal de erotismo: "a poesia conduz ao mesmo ponto como cada forma do erotismo; conduz à indistinção, à fusão dos objetos distintos. Ela nos conduz à eternidade, à morte, e pela morte à continuidade" (BATAILLE, 2017, p. 23).

Vinculada à poeta Alba encontramos também os gêmeos Kuhn, seres que, adotados pela poeta, são resultado de uma relação incestuosa, forçada, entre dois irmãos, e que, por não possuírem braços nem pernas, foram abandonados em um orfanato após o nascimento. Além da poeta estar exercendo uma prática considerada não produtiva em termos econômicos, se contrapondo assim ao mundo do trabalho, os gêmeos, ao se apresentarem nos Altares, também experenciam vivências do excesso. Assim, cada personagem acaba se inserindo em um determinado grupo, em uma comunidade, sublimando a violência que sofrem:

\footnotetext{
Normalmente, os espectadores podem subir ao palco, desde que naquela noite não se apresentem os gêmeos Khun. As performances desses irmãos se desenrolam de tal maneira que os visitantes devem guardar certa distância prudente (BELLATIN, 2001, p.32)
}

As experiências de excesso do escritor, assim como as do Amante Outonal, da poeta Alba e dos gêmeos Khun, cada uma do seu modo, são experiências distintas, que resistem à imposição de modelos normalizados e à exclusão que os mesmos promovem.

Do mesmo modo que as personagens, e intrinsicamente ligados a estas, alguns lugares em Flores também abraçam e sustentam as experiências do excesso, ainda que sofram a coerção do poder através de uma força normalizadora, excludente e coercitiva. Como exemplo encontramos os Altares, locais que se localizam próximo a zona portuária de uma cidade e onde tradicionalmente acontecem espetáculos cujo público espectador é restrito a pessoas cadastradas. São lugares onde se concentram pessoas que buscam sexualidades e vivências alternativas, como é o caso do escritor:

Os depósitos utilizados pelo sindicado dos açougueiros foram construídos
perto do cais da cidade. Entre um e outro há pequenos locais abandonados
que algum dia serviram de refeitórios para os trabalhadores. Quase todos
contam com porões espaçosos onde, em alguns dias da semana,
acontecem os Altares. (...) É possível que se trate de um encontro
sadomasoquista em suas muitas varientes. Às vezes, animais tamabem 
participam das reuniões. Costuma-se escolher, então, leitoas rechonchudas ou dogues alemães. Em outras oportunidades, o Altar é dedicado aos Adultos matratados na infância. Nessas ocasiões, aparecem no palco homens e mulheres com roupas de crianças, fingindo que estão sendo espancados por seus pais e tutores. (BELLATIN, 2001, p.08)

Além dos Altares, há também outro local, o Hell Kitchen, onde se realizam práticas não convencionais relacionadas à sexualidade, e hospeda pessoas que, além de exercerem sua sexualidade de modo não homogêneo, encenam papéis afim de satisfazer seus desejos. É neste local que o escritor, financiado pelo governo local, realiza um trabalho de catalogação e pesquisa, mapeando as sexualidades alternativas que se realizam na cidade:

\begin{abstract}
Neste momento escreve principalmente sobre alguns grupos da zona conhecida como Hell kitchen. Além dos estabelecimentos clássicos dedicados às drag queens e dos bares de mulheres onde se joga bilhar $\mathrm{o}$ tempo todo, o escritor descobriu um grupo de garotas que, vestidas de homem, reúnem-se todas as tardes num lugar de portas douradas (BELLATIN, 2001, p.28).
\end{abstract}

De tal modo, ao se constituírem como espaços do excesso, esses lugares apresentam encenações que dão vazão ao corpo, ao imaginário sexual e ao desenfreamento das sensações, lugares que revelam o potencial do imaginário e das vivências alternativas das personagens que os frequentam. Tais locais são, assim, palco de uma reinvenção da liberdade, que expõe as possibilidades de existência fora dos limites da normalização, e que condizem à liberdade dos corpos que os frequentam e das páticas que neles ocorrem.

\title{
Considerações
}

Se somos constantemente marcados pelo poder disciplinar e destinados à solidão e ao individualismo, a experiência da continuidade através de vivências sexuais, religiosas e de criação que perpassa a vida dos personagens de Flores, nos possibilita certo vislumbre da dissolução desse isolamento e docilidade. Esse mundo bellatiniano da transgressão, que convocou o grotesco, o feio, o anômalo e a fantasia, nos convidou também para um passeio em meio a uma radioativa estufa, da qual -inevitavelmente- saímos contaminados, mas aptos a nos permitir sentir e desejar, a nos permitir buscar o outro, tomar e ser tomado pelo outro.

Assim, se as paixões têm que estar sempre à favor da (contradição que é a) vida, o discurso estético faz essa ponte. O potencial discursivo que Flores apresenta, resgata o urgente 
caos que nos caracteriza, nos impulsiona a nos deixar afetar e ser afetado pelo mar de forças ondulosas do conflito, do devir, dos excessos e do tempo. Se não podemos nos permitir vivenciar diariamente o excesso e experiências de continuidade, a Literatura não apenas representa, mas suscita essas vivências do exagero, da transgressão e da liberdade, e nos impulsiona mais vivamente para brincarmos e jogarmos essa arte (contraditória e complexa) que é vida, ainda que, em meio a esse jogo, encontremos as imperiosas forças do cerceamento e da repressão, das quais devemos sabiamente nos desviarmos.

\section{Referências}

BATAILLE, Georges. O erotismo. Belo Horizonte: Autêntica, 2017.

BELLATIN, Mario. Flores. São Paulo: Cosac Naif, 2001.

FOUCAULT, Michel. Microfísica do poder. Rio de Janeiro: Graal, 1989.

LE BRETON, D. A sociologia do corpo. 4.ed. Petrópolis: Vozes, 2010.

NIETZSCHE, Friedrich. Genealogia da moral: uma polêmica. São Paulo: Best Bolso, 2016.

PRECIADO, Beatriz. Multidões queer: notas para uma política dos "anormais". Revista Estudos Feministas, 2011 